\title{
(2) OPEN ACCESS \\ Five-year change in refractive error and its risk factors: results from the Gutenberg Health Study
}

\author{
Julia V. Stingl (D) ,' Sol A Ban, ${ }^{1}$ Markus Nagler, ${ }^{2}$ Irene Schmidtmann, ${ }^{3}$ \\ Philipp S. Wild, 2,4,5 Karl J. Lackner, ${ }^{6}$ Thomas Münzel, $^{7}$ Manfred E. Beutel, ${ }^{8}$ \\ Norbert Pfeiffer, ${ }^{1}$ Alexander K. Schuster ${ }^{1}$
}

\begin{abstract}
- Additional supplemental material is published online only. To view, please visit the journal online (http://dx.doi. org/10.1136/bjophthalmol2021-318828)
\end{abstract}

For numbered affiliations see end of article.

\section{Correspondence to}

Dr Julia V. Stingl, Department of Ophthalmology, Johannes Gutenberg Universitat Universitätsmedizin Universitäts-Augenklinik Mainz, Mainz 55131, Germany; Julia.sting|@unimedizin-mainz. de

The Association for Research in Vision and Ophthalmology (ARVO) Meeting 2021

Received 11 January 2021 Accepted 23 July 2021

\begin{abstract}
Background/Aims To examine the 5-year change in refractive error in phakic eyes and its risk factors in the general population.

Methods The Gutenberg Health Study (GHS) is a population-based cohort study including 15010 participants from Germany aged 35-74 years at baseline examination (2007-2012). After 5 years, a follow-up examination was carried out (83\% participation). 5-year change of spherical equivalent (SE) was computed as difference between follow-up and baseline objective refraction. Linear and logistic regression analysis were conducted analysing potential risk factors. Only phakic eyes at follow-up examination were included.

Results Right eyes of 10175 subjects were included. An age-related shift of refractive error was identified, namely $-0.12 D$ for age $35-44$ years, $0.25 D$ for age $45-54$ years, $0.25 \mathrm{D}$ for age $55-64$ years and $0.12 \mathrm{D}$ for age $65-74$ years during the 5 -year follow-up. Smokers had a hyperopic shift ( $O R=1.31 ; p<0.001)$, while baseline $S E(O R=0.89$ per dioptre; $p<0.001)$ and female sex $(O R=1.49 ; p<0.001)$ were linked with a myopic shift. Education, occupation and other cardiovascular parameters were not associated with change in refractive error.

Conclusions The GHS demonstrates a parabolic shift in refractive error with a myopic shift at age 35-44 years, followed by a hyperopic shift at age 45-64 years which decreases at higher age. Smoking is associated with a hyperopic shift whereas female sex and myopic baseline $\mathrm{SE}$ is associated with a myopic shift. Educational level and occupation were not linked to a change in refractive error at age $35-74$ years.
\end{abstract}

\section{INTRODUCTION}

Refractive error is the main cause of visual impairment worldwide. ${ }^{12}$ It is the inability of the eye to display a sharp picture on the retina. Refractive error can be corrected by spectacles, contact lenses or refractive surgery, but still constitutes an important risk factor for different ophthalmological diseases such as angle closure glaucoma in hyperopic individuals or open angle glaucoma, ${ }^{3}$ retinal detachment ${ }^{4}$ and myopic maculopathy in the case of myopia. ${ }^{5}$

The global prevalence for myopia is $26.5 \%$, and $30.9 \%$ for hyperopia, ${ }^{6}$ whereas in Germany prevalence for myopia and hyperopia is $35.1 \%$ and $31.8 \%$, respectively. ${ }^{7}$ The prevalence of myopia is steadily increasing and is estimated to affect about 5 billion individuals worldwide by $2050 .^{8}$
The development of myopia is decisively influenced by both hereditary and environmental risk factors. ${ }^{9} 10$ Various genes were identified to be responsible for myopia, most of them affecting the retinal and choroidal tissue, their signal transduction and cell-cycle mechanisms supporting the hypothesis of light-dependent globe growth. ${ }^{10}{ }^{11} \mathrm{~A}$ higher educational level was associated with a more myopic refraction, ${ }^{12}{ }^{13}$ and there are two major theories explaining this relation: first, near work over longer periods may lead to reduced accomodation ability resulting in hyperopic defocus on the retina and in eye growth, as shown in animal models. ${ }^{14}$ Second, bright light seems to release dopamine which is postulated to inhibit axial elongation, ${ }^{15}$ and increased time spent outside showed a preventive effect regarding myopia in adolescents. ${ }^{1617}$

It is well known that refractive error can change over lifetime. A hyperopic shift is described in younger subjects between 35 and 64 years, whereas people aged 65 and older undergo a myopic shift. ${ }^{18} 19$ The hyperopic shift in younger adults has been attributed to decreasing lens power, and the myopic shift to nuclear cataract. ${ }^{20}$ Interestingly, people with high myopia seem to have a smaller hyperopic shift than emmetropic or hyperopic people. ${ }^{18}$ Furthermore, higher education was associated with a higher hyperopic shift after 6 years in a Chinese cohort aged $\geq 35$ years and in the Blue Mountains Eye Study cohort aged $\geq 49$ years after 5 years. ${ }^{18} 19$

In previous studies, not only associations with age, lens opacification or baseline refractive error, but also with cardiovascular risk factors such as arterial hypertension or diabetes mellitus were found. ${ }^{2122}$ Diabetes mellitus can cause lens swelling by blood glucose fluctuations and is further a known risk factor for cataract development. ${ }^{23}{ }^{24}$ Also, dyslipidaemia has been identified as risk factor for cortical opacification, ${ }^{25}$ which may affect the course of refractive error.

However, apart from this, there is little knowledge about the course of refractive error in adults. The purpose of this study therefore is to analyse changes in refractive error of adults and to identify further risk factors associated with refractive error change.

\section{METHODS}

The Gutenberg Health Study (GHS) is a prospective and observational population-based cohort 
study in the State of Rhine-Palatine, Germany. Fifteen thousand and ten residents, randomly sampled by the regional registration office, took part. The study participants had an age range from 35 to 74 years at inclusion. The study was launched in 2007 and comprises an extensive follow-up examination at an interval of 5 years. The study design has been previously published by Höhn et $a{ }^{26}{ }^{26}$ Inclusion criteria for the GHS were mental and physical ability to visit the study centre and to pass through the examinations, sufficient knowledge of the German language.

The baseline examination took place between 2007 and 2012 and a follow-up examination after 5 years between 2012 and 2017 at the study center at University Medical Center Mainz.

An ophthalmological examination was conducted including a slit-lamp examination at baseline, corneal Scheimpflug imaging (baseline: Pachycam, follow-up examination: Pentacam, Oculus, Wetzlar, Germany), determination of visual acuity, objective refraction (Humphrey Automated Refractor/Keratometer (HARK) 599, Carl Zeiss Meditec AG, Jena, Germany) and noncontact tonometry (Nidek NT-2000, Nidec Co, Japan).

Refractive error measurement was conducted without cycloplegia. Refractive values were measured in spherical and cylindrical dioptres (D), cylindrical power was indicated in negative sign convention. Spherical equivalent (SE) was computed as $\mathrm{SE}=$ sphere $+0.5 \times$ cylinder. No refractive change was defined as -0.5 to $+0.5 \mathrm{D}$ change in SE, myopic shift as $<-0.5 \mathrm{D}$ and hyperopic shift as $>+0.5 \mathrm{D}$. Presence of cataract was evaluated during slit-lamp examination in neutral pupil size at baseline.

Educational level ${ }^{12}$ and occupation were investigated. Job position was classified via KIdB 2010 ('Klassifikation der Berufe'-German classification of occupations) in nine categories with additional subgroups for unemployed subjects, retired subjects and homemaker. One military subject was added to the 'Traffic, logistics, protection and security' category.

Physical activity was assessed using the SQUASH (Short QUestionnaire to ASses Health-enhancing physical activity) physical activity questionnaire and is indicated as physical activity score in minutes $\times$ intensity per week. ${ }^{27}$ Extensive laboratory measurements including glycated hemoglobin (HbA1c), vitamin D level and blood lipid levels were carried out. Anthropometric measurements were performed with calibrated digital scales (Seca 862, Seca, Hamburg, Germany) and a measuring stick (Seca 220, Seca, Hamburg, Germany), and body mass index (BMI) was computed as $\mathrm{BMI}=$ weight $/$ height $^{2}$. Smoking information is provided as categorical variable with four levels: nonsmoker, occasional smoker, smoker and former smoker.

\section{Study sample}

All study participants with objective refraction measurement at both baseline and 5-year follow-up examination were included. Refractive change was computed as difference in SE between follow-up and baseline measurement. If data were only available for one eye at both time points, this eye was included. For descriptive statistics, only right eyes were included. Exclusion criteria were ocular surgeries and only phakic eyes were included.

\section{Statistics}

Descriptive statistics were calculated for all primary and secondary variables. For categorical data, absolute and relative frequencies were computed. For continuous parameters, mean and SD was calculated for all approximately normally distributed variables, otherwise median and interquartile range (IQR).

The distribution of 5-year change in SE was computed for the total analysis sample, as well as age-stratified and sex-stratified.
Multiple linear and logistic regression analyses with generalised estimating equations (on eye-level) were performed to evaluate associated factors with 5 -year change in SE. The included baseline parameters were sex, age (in linear and quadratic term), SE, intraocular pressure, presence of cataract, cardiovascular parameters such as HbA1c, high-density lipoprotein (HDL)-cholesterol, low-density lipoprotein (LDL)-cholesterol, triglycerides, BMI, physical activity and smoking as well as level of education and occupation. In logistic regression analysis, hyperopic and myopic shift was compared against no refractive change $(-0.5 \mathrm{D} \leq \mathrm{x} \leq 0.5$ D). This is an exploratory study, $\mathrm{p}$ values were considered statistically significant if they were less than 0.05 . Statistical analysis was performed with R (V.3.6.1).

\section{RESULTS}

Among the initial 15010 subjects, 12423 visited the study centre for the 5-year follow-up examination. Two thousand two hundred and twenty-two subjects were excluded due to corneal surgery or cataract surgery in both eyes. Objective refractive data were not available from both baseline and 5-year follow-up examination in another 26 subjects resulting in the analysis sample of 10175 subjects (9978 right eyes and 9952 left eyes). Table 1 shows the characteristics of analysis sample at baseline. The mean age was $53.0 \pm 10.4$ years at baseline, and $52.6 \%$ were women.

The median value of refractive errors among included subjects was -0.12 (IQR: $-1.25 ; 0.75$ ) in right and in left eyes at baseline. The median value of refractive change over 5 years showed an overall hyperopic shift of $0.12 \mathrm{D}$ in the right eyes. Separated into age decades, the 5 years change in SE was $-0.12 \mathrm{D}$ for age 35-44 years, $0.25 \mathrm{D}$ for $45-54$ years, $0.25 \mathrm{D}$ for $55-64$ years and $0.12 \mathrm{D}$ for $65-74$ years, respectively. At age $65-74$ years, women showed no hyperopic shift in contrast to men (table 2). The scatterplot shows a quadratic relationship between 5 -year change in SE and age with a hyperopic shift between age 44 and 70 years and a myopic shift at younger and higher age (figure 1).

The multivariable linear regression analysis showed a myopic shift over time in women compared with the men, age was associated in a negative quadratic relationship. Intraocular pressure (IOP), presence of cataract, HbA1c, HDL-cholesterol, LDL-cholesterol, triglycerides, BMI, physical activity, educational level and occupation were not associated with 5-year change of SE (table 3). In the logistic regression analysis, a myopic shift (more than $-0.5 \mathrm{D})$ was related to lower age $(\mathrm{p}<0.001)$, female sex $(\mathrm{OR}=1.49, \mathrm{p}<0.001)$ and baseline myopic $\mathrm{SE}(\mathrm{OR}=0.89$ per diopter, $\mathrm{p}<0.001)$ (online supplemental table 1 ). A hyperopic shift (more than $0.5 \mathrm{D}$ ) was more likely at higher age $(\mathrm{p}<0.001)$ and in regular smoker compared with non-smoker $(\mathrm{OR}=1.31, \mathrm{p}<0.001)$, while former smoking or occasional smoking was not associated in logistic regression analysis (online supplemental table 2).

\section{DISCUSSION}

Refractive error has a major impact on visual impairment worldwide, especially in low-income and middle-income countries. Change of refractive error is not only a phenomenon of childhood and young adulthood, as shown in large cohort studies involving individuals of European, ${ }^{28}$ American, ${ }^{20}$ Australian, ${ }^{19}$ Carribean $^{29}$ and Asian ${ }^{21}$ origin during the last two decades. The aim of this study was to analyse the 5-year change in SE and to identify risk factors in a large German cohort aged 35-74 years within the scope of the GHS.

The main findings of this study were a median age-related shift of refractive error of $-0.12 \mathrm{D}, 0.25 \mathrm{D}, 0.25 \mathrm{D}$ and $0.12 \mathrm{D}$ for age groups $35-44,45-54,55-64$ and 65-74 years. Regular smokers 
Table 1 Baseline characteristics of the analysis sample with data on refractive error change in phakic eyes

\begin{tabular}{|c|c|c|c|}
\hline Characteristics & Total & Males & Females \\
\hline$n$ & 10175 & 5243 & 4932 \\
\hline Sex (female) & $48.5 \%$ & - & - \\
\hline Age (years) & $53.5( \pm 10.5)$ & $53.7( \pm 10.6)$ & $53.2( \pm 10.4)$ \\
\hline \multicolumn{4}{|l|}{ Ocular parameters (right eyes) } \\
\hline Sphere (D) & $0(-1.00 ; 1.00)$ & $0(-1.00 ; 1.00)$ & $0(-1.00 ; 1.00)$ \\
\hline Cylinder (D) & $-0.50(-0.75 ; 0)$ & $-0.50(-0.75 ;-0.25)$ & $-0.50(-0.75 ; 0)$ \\
\hline Spherical equivalent (D) & $-0.12(-1.25 ; 0.75)$ & $-0.12(-1.25 ; 0.75)$ & $-0.12(-1.12 ; 0.88)$ \\
\hline IOP (mm Hg) & $14.10( \pm 2.78)$ & $14.16( \pm 2.86)$ & $14.03( \pm 2.68)$ \\
\hline \multicolumn{4}{|l|}{ Ocular parameters (left eyes) } \\
\hline Sphere (D) & $0(-1.00 ; 1.00)$ & $0(-1.00 ; 1.00)$ & $0(-1.00 ; 1.00)$ \\
\hline Cylinder (D) & $-0.50(-0.75 ; 0)$ & $-0.50(-0.75 ; 0)$ & $-0.25(-0.75 ; 0)$ \\
\hline Spherical equivalent (D) & $-0.12(-1.25 ; 0.75)$ & $-0.12(-1.25 ; 0.75)$ & $0(-1.25 ; 0.88)$ \\
\hline IOP (mm Hg) & $14.25( \pm 2.83)$ & $14.37( \pm 2.91)$ & $14.11( \pm 2.72)$ \\
\hline \multicolumn{4}{|l|}{ Ocular diseases } \\
\hline Cataract (slitlamp examination) OD & $25.2 \%$ & $24.8 \%$ & $25.5 \%$ \\
\hline Cataract (slitlamp examination) OS & $23.8 \%$ & $23.2 \%$ & $24.4 \%$ \\
\hline \multicolumn{4}{|l|}{ Cardiovascular risk profile } \\
\hline \multicolumn{4}{|l|}{ Smoking } \\
\hline Never & $46.5 \%$ & $40.1 \%$ & $53.4 \%$ \\
\hline Former smoker & $34.9 \%$ & $40.2 \%$ & $29.2 \%$ \\
\hline Occasional smoker & $1.6 \%$ & $1.7 \%$ & $1.5 \%$ \\
\hline Smoker & $17.0 \%$ & $18.0 \%$ & $16.0 \%$ \\
\hline Obesity (yes) & $23.2 \%$ & $24.6 \%$ & $21.8 \%$ \\
\hline Diabetes (yes) & $6.9 \%$ & $8.6 \%$ & $5.0 \%$ \\
\hline Dyslipidaemia (yes) & $32.4 \%$ & $41.2 \%$ & $23.1 \%$ \\
\hline Hypertension (yes) & $46.3 \%$ & $51.9 \%$ & $40.3 \%$ \\
\hline Body mass index $\left(\mathrm{kg} / \mathrm{m}^{2}\right)$ & $26.4(23.8 ; 29.7)$ & $27.1(24.8 ; 29.9)$ & $25.4(22.6 ; 29.2)$ \\
\hline Physical activity (minutesxintensity/week) & $7701.3( \pm 3909.0)$ & $7772.5( \pm 4231.5)$ & $7621.2( \pm 3510.1)$ \\
\hline \multicolumn{4}{|l|}{ Laboratory measures } \\
\hline $\mathrm{HbA1c}(\%)$ & $5.5(5.2 ; 5.8)$ & $5.5(5.2 ; 5.8)$ & $5.4(5.2 ; 5.7)$ \\
\hline HDL-cholesterol (mg/dL) & $57.5( \pm 15.5)$ & $50.4( \pm 12.0)$ & $65.0( \pm 15.2)$ \\
\hline LDL-cholesterol (mg/dL) & $139.0( \pm 35.0)$ & $139.5( \pm 34.5)$ & $138.5( \pm 35.5)$ \\
\hline Triglycerides (mg/dL) & $103.0(77.0 ; 144.0)$ & $116.0(85.4 ; 162.0)$ & $93.0(70.4 ; 124.0)$ \\
\hline \multicolumn{4}{|l|}{ Education } \\
\hline Secondary gerneral school ('Hauptschule') & $34.9 \%$ & $35.7 \%$ & $34.2 \%$ \\
\hline Intermediate school ('Realschule') & $23.6 \%$ & $18.0 \%$ & $29.6 \%$ \\
\hline High school ('Abitur') & $40.5 \%$ & $45.6 \%$ & $35.2 \%$ \\
\hline Others & $0.5 \%$ & $0.4 \%$ & $0.6 \%$ \\
\hline None & $0.4 \%$ & $0.4 \%$ & $0.5 \%$ \\
\hline \multicolumn{4}{|l|}{ Occupation } \\
\hline Housemaker, retried or none & $35.9 \%$ & $30.1 \%$ & $42.2 \%$ \\
\hline Agriculture, forestry, animal husbandry and horticulture & $2.0 \%$ & $2.9 \%$ & $1.0 \%$ \\
\hline Production and manufacturing & $8.7 \%$ & $14.5 \%$ & $2.5 \%$ \\
\hline Construction and architecture & $3.2 \%$ & $5.7 \%$ & $0.5 \%$ \\
\hline Natural and computer science & $4.6 \%$ & $7.3 \%$ & $1.8 \%$ \\
\hline Transport, logistics, security and military & $5.2 \%$ & $7.8 \%$ & $2.5 \%$ \\
\hline Commercial services and tourism & $6.3 \%$ & $5.6 \%$ & $7.0 \%$ \\
\hline Business organisation, accounting, law and administration & $18.9 \%$ & $15.9 \%$ & $22.1 \%$ \\
\hline Health and education & $12.2 \%$ & $7.2 \%$ & $17.6 \%$ \\
\hline Humanities, media and culture & $2.9 \%$ & $3.0 \%$ & $2.9 \%$ \\
\hline
\end{tabular}

Data from the German population-based Gutenberg Health Study (2007-2017). Analysis sample included 10175 subjects (9978 right eyes and 9952 left eyes).

Mean \pm SD are shown for normally distributed parameters, and median and IQR are shown for not normally distributed parameters.

HbA1c, Glycated hemoglobine; HDL, High-density lipoprotein; IOP, intraocular pressure; LDL, Low-density lipoprotein; OD, Oculus dexter; OS, Oculus sinister.

were at higher risk for a hyperopic shift, and women were more likely to have a myopic shift. Education and occupation were not associated with refractive change after the age of 35 years.

Several studies have described a hyperopic shift in age groups under 65 years, followed by a myopic shift beginning at the age of 60-65 years. ${ }^{18-22}{ }^{28-30}$ Our data confirmed this trend. While participants aged 35-44 years showed a myopic shift within the following 5 years, older participants (45-64 years) had a hyperopic shift which decreased in the oldest age group. The overall change of SE over a 5-year interval showed a hyperopic shift 


\begin{tabular}{|c|c|c|c|c|c|c|}
\hline \multirow[b]{2}{*}{$\begin{array}{l}\text { Baseline } \\
\text { age }\end{array}$} & \multicolumn{3}{|c|}{$\begin{array}{l}5 \text {-year change in spherical } \\
\text { equivalent (D) }\end{array}$} & \multicolumn{3}{|c|}{$\begin{array}{l}\text { Per cent with 5-year } \\
\text { changes }\end{array}$} \\
\hline & $\mathrm{n}$ & Median & IQR & $<-0.5 \mathrm{D}$ & $\begin{array}{l}-0.5 \\
\text { to }+0.5 \mathrm{D}\end{array}$ & $\begin{array}{l}>0.5 \\
D\end{array}$ \\
\hline \multicolumn{7}{|l|}{ Both sexes } \\
\hline 35-44 & 2441 & -0.12 & $-0.38 ; 0.25$ & 12.0 & 80.4 & 7.6 \\
\hline $45-54$ & 2999 & 0.25 & $0 ; 0.50$ & 3.4 & 81.3 & 15.3 \\
\hline $55-64$ & 2744 & 0.25 & $0 ; 0.50$ & 4.2 & 79.9 & 15.9 \\
\hline $65-74$ & 1794 & 0.12 & $-0.25 ; 0.38$ & 13.3 & 76.8 & 9.9 \\
\hline All ages & 9978 & 0.12 & $-0.12 ; 0.38$ & 7.5 & 79.9 & 12.6 \\
\hline \multicolumn{7}{|l|}{ Males } \\
\hline $35-44$ & 1208 & -0.12 & $-0.38 ; 0.12$ & 10.8 & 82.8 & 6.5 \\
\hline $45-54$ & 1537 & 0.25 & $0 ; 0.50$ & 2.9 & 82.8 & 14.3 \\
\hline $55-64$ & 1402 & 0.25 & $0 ; 0.50$ & 3.2 & 80.2 & 16.5 \\
\hline $65-74$ & 987 & 0.12 & $-0.25 ; 0.38$ & 12.2 & 77.2 & 10.6 \\
\hline All ages & 5134 & 0.12 & $-0.12 ; 0.38$ & 6.6 & 81.0 & 12.4 \\
\hline \multicolumn{7}{|l|}{ Females } \\
\hline $35-44$ & 1233 & -0.12 & $-0.38 ; 0.25$ & 13.2 & 78.1 & 8.7 \\
\hline $45-54$ & 1462 & 0.25 & $0 ; 0.50$ & 3.9 & 79.8 & 16.3 \\
\hline $55-64$ & 1342 & 0.25 & $0 ; 0.38$ & 5.2 & 79.5 & 15.3 \\
\hline $65-74$ & 807 & 0 & $-0.25 ; 0.26$ & 14.6 & 76.3 & 9.0 \\
\hline All ages & 4844 & 0.12 & $-0.12 ; 0.38$ & 8.4 & 78.7 & 12.9 \\
\hline
\end{tabular}

Data from the German population-based Gutenberg Health Study (2007-2017). *Small deviation from $100 \%$ in total may appear due to mathematical rounding of the numbers.

of $+0.12 \mathrm{D}$ slightly lower than in previous studies. The Blue Mountains Eye Study found a mean refractive error change of $+0.19 \mathrm{D},{ }^{19}$ the Handan Eye Study of $+0.17 \mathrm{D}^{21}$ and +0.29 $\mathrm{D}$ was reported in the Reykjavik Eye Study, ${ }^{28}$ while the Beaver Dam Eye Study found the same hyperopic shift $(+0.12 \mathrm{D}){ }^{22}$ implicating similar changes in both Caucasian and Asian eyes. Nevertheless, the studies had different age-ranges and the results are therefore not directly comparable. The age distribution of previous studies may explain the difference in overall refractive change because less subjects at younger age having a myopic shift were included in these studies.
The myopic shift at younger age, identified in our analysis, was also seen in the Handan Eye Study and might be attributable to continuing of progressive myopia into adulthood. ${ }^{21}$ In accordance with this, we found more likely a myopic shift (over $-0.5 \mathrm{D}$ ) in subjects with a higher myopic baseline refractive error.

The aetiology of the hyperopic shift at age $43-70$ years is so far not completely understood. Some authors hypothesised that the decreasing ability to accommodate is at least partially responsible, but studies using cycloplegic refraction as in Beaver Dam Eye Study also found a comparable hyperopic shift. ${ }^{22}$ Another possible explanation is that the human lens power, which is formed by a refractive index gradient profile - unlike the homogeneous lens structures of intraocular lenses - decreases over the course of a lifetime. A maximum of lens fibre condensation in the central lens will be reached in adulthood, which causes an index plateau and acts like a homogeneous lens structure without a gradient, leading to a lower lens power. ${ }^{31}$ The results of a recent population-based study in China support this theory as they found a relation between the hyperopic shift and the decreasing lens power. ${ }^{18}$ At higher age, the identified myopic shift is in accordance to literature ${ }^{32}$ and is known to be caused by nuclear cataract, ${ }^{18}$ while other cataracts rather lead to a hyperopic shift. ${ }^{33}$ This is explained by a combined effect of a refractive index change of the lens in nuclear cataract and a lens curvature change in cortical cataract. ${ }^{33}$ The Beaver Dam Eye Study reported a 5-year refractive shift of $-0.72 \mathrm{D}$ in eyes with severe nuclear sclerosis compared with eyes with only mild nuclear sclerosis, ${ }^{22}$ confirmed by other cohort studies describing a strong association between myopic shift and nuclear sclerosis. ${ }^{192228293435}$ Contrarily, in this study presence of cataract was not associated with a change in refractive error. This may be explained by missing differentiation of nuclear and cortical cataract in slit-lamp examination in neutral pupil size.

Although a higher educational level was found to be associated with a more myopic refractive error in the baseline GHS analysis, ${ }^{12}$ both educational level and occupation did not influence the change of refractive error over the observed period of 5 years. This is in line with the Beaver Dam Eye Study and the Barbados Eye Study. In contrast, the Blue Mountains Eye Study and a Chinese population-based study showed that individuals

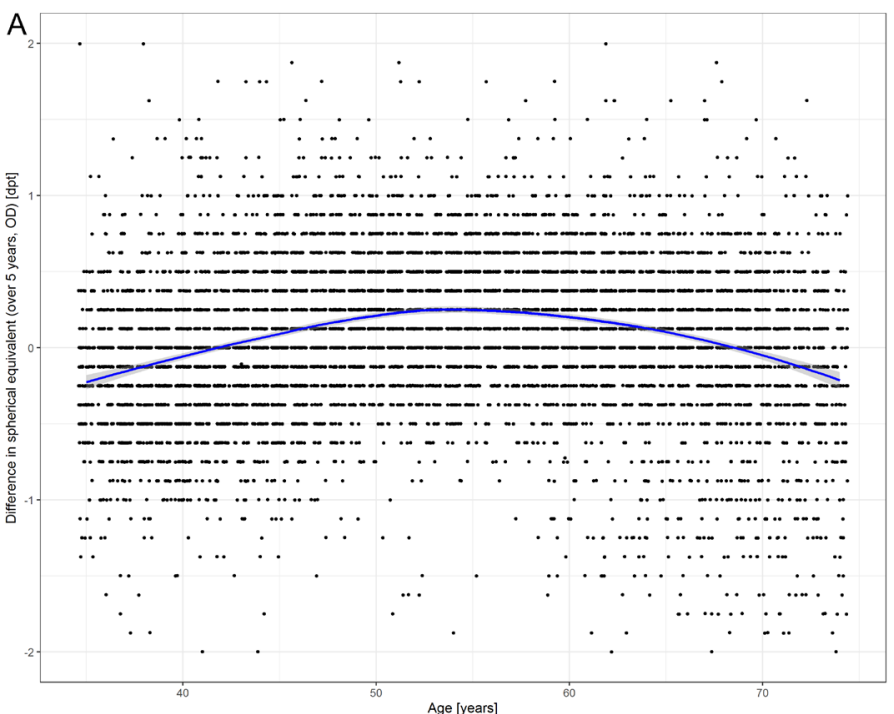

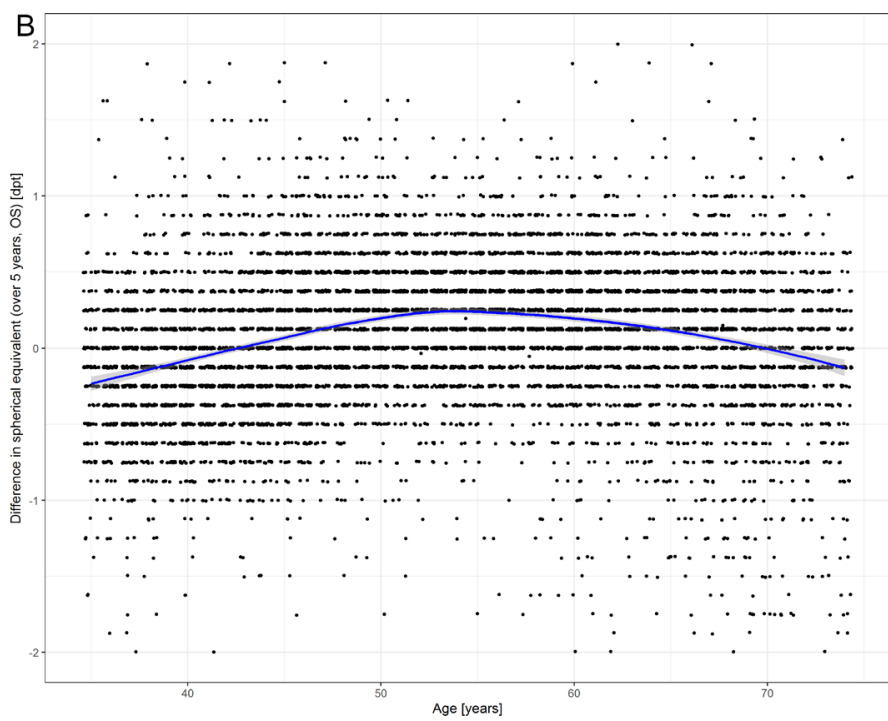

Figure 1 Five-year change in spherical equivalent in phakic eyes and its relation to age. Data from the German population-based Gutenberg Health Study (2007-2017). (A) Right eyes; (B) left eyes. 
Table 3 Associations with 5-year change in spherical equivalent in phakic eyes

\begin{tabular}{|c|c|c|c|}
\hline ( $n=15836$ eyes) & Beta & $95 \% \mathrm{Cl}$ & $P$ value \\
\hline Sex (female) & -0.043 & -0.080 to 0.005 & 0.027 \\
\hline \multicolumn{4}{|l|}{ Age (per year) } \\
\hline Linear term & 0.139 & 0.12 to 0.15 & $<0.001$ \\
\hline Quadratic term & -0.001 & -0.0014 to -0.0011 & $<0.001$ \\
\hline \multicolumn{4}{|l|}{ Cardiovascular parameters } \\
\hline HbA1c (\%) & 0.011 & -0.040 to 0.019 & 0.49 \\
\hline HDL-cholesterol (mg/dL) & 0.000 & -0.0010 to 0.0015 & 0.69 \\
\hline LDL-cholesterol (mg/dL) & 0.000 & -0.0002 to 0.0007 & 0.30 \\
\hline Triglycerides (mg/dL) & 0.000 & -0.0003 to 0.0004 & 0.71 \\
\hline BMI $\left(\mathrm{kg} / \mathrm{m}^{2}\right)$ & -0.002 & -0.007 to 0.004 & 0.55 \\
\hline Physical activity & 0.000 & $>-0.001$ to $<0.001$ & 0.14 \\
\hline \multicolumn{4}{|l|}{ Smoking history } \\
\hline Non-smoker & & Reference & \\
\hline Smoker & 0.030 & 0.012 to 0.072 & 0.16 \\
\hline Occasional smoker & -0.050 & -0.174 to 0.074 & 0.43 \\
\hline Former smoker & 0.023 & -0.012 to 0.057 & 0.19 \\
\hline \multicolumn{4}{|l|}{ Ocular parameters } \\
\hline Spherical equivalent (D) & -0.015 & -0.033 to 0.002 & 0.085 \\
\hline IOP $(\mathrm{mm} \mathrm{Hg})$ & -0.003 & -0.009 to 0.003 & 0.34 \\
\hline Lens opacity & -0.001 & -0.039 to 0.039 & 0.98 \\
\hline \multicolumn{4}{|l|}{ Education } \\
\hline $\begin{array}{l}\text { Secondary gerneral school } \\
\text { ('Hauptschule') }\end{array}$ & & Reference & \\
\hline Intermediate school ('Realschule') & 0.013 & -0.03 to 0.08 & 0.57 \\
\hline High school ('Abitur') & 0.000 & -0.04 to 0.04 & 0.98 \\
\hline Others & 0.031 & -0.12 to 0.17 & 0.66 \\
\hline None & 0.049 & -0.11 to 0.21 & 0.55 \\
\hline \multicolumn{4}{|l|}{ Occupation } \\
\hline Housemaker, retried or none & & Reference & \\
\hline $\begin{array}{l}\text { Agriculture, forestry, animal } \\
\text { husbandry and horticulture }\end{array}$ & -0.050 & -0.17 to 0.07 & 0.42 \\
\hline Production and manufacturing & -0.006 & -0.05 to 0.06 & 0.83 \\
\hline Construction and architecture & 0.009 & -0.10 to 0.12 & 0.87 \\
\hline Natural and computer science & 0.054 & -0.03 to 0.14 & 0.21 \\
\hline $\begin{array}{l}\text { Transport, logistics, security and } \\
\text { military }\end{array}$ & -0.051 & -0.11 to 0.01 & 0.10 \\
\hline Commercial services and tourism & 0.004 & -0.06 to 0.06 & 0.89 \\
\hline $\begin{array}{l}\text { Business organisation, accounting, } \\
\text { law and administration }\end{array}$ & 0.006 & -0.04 to 0.06 & 0.80 \\
\hline Health and education & -0.001 & -0.05 to 0.05 & 0.98 \\
\hline Humanities, media and culture & 0.038 & -0.05 to 0.13 & 0.42 \\
\hline
\end{tabular}

Data from the German population-based Gutenberg Health Study (2007-2017). Multivariable linear regression analysis with generalised estimating equations was conducted. Bold values indicate statistical significance $(p<0.05)$.

HbA1c, Glycated hemoglobin; HDL, High-density lipoprotein; IOP, intraocular pressure; LDL, Low-density lipoprotein.

with higher education had a higher hyperopic shift, ${ }^{19} 2229$ while the Handan Eye Study found an association between educational level and a myopic shift in univariate but not in multivariable analysis. ${ }^{21}$ This study is the first to show that occupational activities do not affect refractive error beyond the age of 35 years on population-based level.

Higher IOP is associated with longer axial length in children and also in young adulthood (18-27 years). ${ }^{36} 37$ This effect possibly continues in older age groups but to a smaller amount, as published in the Barbados Eye Study, where individuals with ocular hypertension were at higher risk for incidence of myopia over an observation period of 9 years. ${ }^{29}$ In our regression models, no association of IOP with change in refractive error was found. Furthermore, the Handan Eye Study reported that ocular hypertension was identified as a risk factor for a hyperopic shift in Asians. $^{21}$

Although no association between smoking information and refractive error change was seen in the linear regression analysis, smokers were at higher risk to develop a hyperopic shift (more than +0.5 D) than non-smokers, former smokers or occasional smokers in the logistic regression analysis. Reykjavik Eye Study was the only other study that included the risk factor smoking in a regression model, but did not find any association with the change in SE. ${ }^{28}$ The Salisbury Eye Evaluation Study reported that current smoking is associated with nuclear opacity incidence and progression, as well as cortical opacity progression. ${ }^{38}$ This demonstrates that smoking leads to changes of the lens structure, that might result in a hyperopic refractive shift as found in our cohort.

We did not find any relation between refractive change and HbA1c-level as a marker for blood sugar control. In contrast, the Beaver Dam Eye Study found a more hyperopic shift in individuals with diabetes, ${ }^{22}$ whereas Handan Eye study reported a more myopic shift and explained this by lens swelling leading to an increased refractive index, ${ }^{21}$ while the Blue Mountains Eye Study did not find an association. ${ }^{19}$ There was no association between HDL-cholesterol, LDL-cholesterol and triglycerides and the change in refractive error, though previous studies found an association between dyslipidaemia and cataract development, ${ }^{25}$ which possibly might affect the refractive change. Furthermore, no relation between baseline refractive error and overall refractive change was present in the linear regression model, which is consistent with the 5-year data form the Beaver Dam Eye Study. Though in our study, logistic regression analysis showed a higher risk for a myopic shift in subjects with a higher myopic baseline refractive error. The Handan Eye Study reported a more myopic shift in individuals with longer axial length and postulated a higher fragility of the scleral tissue resulting in a higher tendency to expand. ${ }^{21}$

There are some limitations of our study. First, the recruitment efficacy proportion of our study was only $55.5 \%$ at baseline, nevertheless over $83 \%$ of the study participants took part in the 5 -year follow-up examination. Second, we only had a slit-lamp examination with natural pupil at baseline and Scheimpflug imaging with natural pupil at 5-year follow-up examination and could therefore not evaluate the degree of lens opacity, subtypes of cataract and the cataract status after 5 years. Thus, the calculation of lens opacity influencing refractive error change might be imprecise. Nuclear sclerosis has been made responsible for the myopic shift in elderly people in previous studies. ${ }^{19} 2228293435$ In addition, ocular biometry was only carried out at the 5 -year follow-up examination and we cannot report whether the change in refraction is due to an alteration of the ocular geometry or due to change in refractive index, especially of the human lens. Han et $a l^{18}$ previously showed that lens power change was the most important biometric parameter for refractive changes at age 35 years and older. Another major limitation is the lacking information about the age of onset of myopia, which was associated with refractive change in both Blue Mountain Eye Study and Beaver Dam Eye Study. ${ }^{19} 22$

In summary, the GHS demonstrates a parabolic shift in refractive error with a myopic shift at age 35-44 years, while subjects at 45-64 years had a hyperopic shift which decreased in the oldest age group (65-74 years). Smoking was associated with a hyperopic shift whereas female sex and myopic baseline SE was 
associated with a myopic shift. Educational level and occupation did not have any effect on refractive change after 5 years at age $35-74$ years.

\section{Author affiliations \\ ${ }^{1}$ Department of Ophthalmology, University Medical Center of the Johannes Gutenberg University Mainz, Mainz, Germany \\ ${ }^{2}$ Preventive Cardiology and Preventive Medicine, Center for Cardiology, University Medical Center of the Johannes Gutenberg University Mainz, Mainz, Germany ${ }^{3}$ Institute for Medical Biostatistics, Epidemiology and Informatics, University Medical Center of the Johannes Gutenberg University Mainz, Mainz, Germany ${ }^{4}$ Center for Thrombosis and Hemostasis (CTH), University Medical Center of the Johannes Gutenberg University Mainz, Mainz, Germany \\ ${ }^{5}$ German Center for Cardiovascular Research (DZHK), partner site Rhine-Main, Mainz, Germany \\ ${ }^{6}$ Institute for Clinical Chemistry and Laboratory Medicine, University Medical Center of the Johannes Gutenberg University Mainz, Mainz, Germany \\ ${ }^{7}$ Center for Cardiology - Cardiology I, University Medical Center of the Johannes Gutenberg University Mainz, Mainz, Germany \\ ${ }^{8}$ Psychosomatic Medicine and Psychotherapy, University Medical Center of the Johannes Gutenberg University Mainz, Mainz, Germany}

Contributors The authors are justifiably credited with authorship, according to the authorship criteria. In detail: JVS and SAB - data analysis and interpretation, manuscript preparation and final revision. $\mathrm{MN}$ - major part of data analysis and final revision. IS, PSW, KJL, TM, MB and NP-research design and execution, data acquisition, revision and final approval. AS - data acquisition and research execution, data analysis and interpretation, manuscript preparation and a final revision.

Funding All authors: the Gutenberg Health Study is funded through the government of Rhineland-Palatinate ('Stiftung Rheinland-Pfalz für Innovation', contract AZ 961-386261/733), the research programmes 'Wissen schafft Zukunft' and 'Center for Translational Vascular Biology (CTVB)' of the Johannes GutenbergUniversity of Mainz, and its contract with Boehringer Ingelheim and PHILIPS Medical Systems, including an unrestricted grant for the Gutenberg Health Study. Funders were involved in the development of the study design as scientific consultants. The funders had no role in study design, data collection and analysis, decision to publish or preparation of the manuscript. AKS holds the professorship for ophthalmic healthcare research endowed by 'Stiftung Auge' and financed by 'Deutsche Ophthalmologische Gesellschaft' and 'Berufsverband der Augenärzte Deutschlands e.V'. PSW is funded by the Federal Ministry of Education and Research (BMBF 01E01503) and he is the PI of the German Center for Cardiovascular Research (DZHK). NP receives financial support from Novartis, Ivantis, Santen, Thea, Boehringer Ingelheim Deutschland GmbH \& Co. KG, Alcon and Sanoculis. MB received speaker honorarium from Pfizer Deutschland $\mathrm{GmbH}$, Shire Deutschland $\mathrm{GmbH}$ and currently receives research grants from the governments of Rhineland-Palatinate and Nordrhein-Westfalen, the German Association of Psychoanalysis and Psychotherapy (DGPT), the German Research Foundation, the German Ministry of Research, the German Cancer Aid and the European Union.

Competing interests NP receives financial support and grants from Novartis, Ivantis, Santen, Thea, Boehringer Ingelheim Deutschland GmbH \& Co. KG, Alcon, and Sanoculis. AKS receives research support from Allergan, Bayer Vital, Novartis, PlusOptix, and Heidelberg Engineering.

\section{Patient consent for publication Not required.}

Ethics approval Each participant gave written informed consent, and the study was conducted in accordance with the Declaration of Helsinki. Approvals of the local ethics committee (Ethics Commission of the State Chamber of Physicians of Rhineland-Palatinate, reference no. 837.020.07; original vote: 22.3.2007, latest update: 20.10 .2015 ) and local and federal data safety commissioners were obtained.

\section{Provenance and peer review Not commissioned; externally peer reviewed.}

Data availability statement The written informed consent of GHS study participants does not approve public access to the data. This concept was requested by the local data protection officer and ethics committee (local ethics committee of the Medical Chamber of Rhineland-Palatinate, Germany). Access to data at the local database in accordance with the ethics vote is offered upon request at any time. Interested researchers can make their requests to the Principal Investigators of the Gutenberg Health Study (email: info@ghs-mainz.de).

Supplemental material This content has been supplied by the author(s). It has not been vetted by BMJ Publishing Group Limited (BMJ) and may not have been peer-reviewed. Any opinions or recommendations discussed are solely those of the author(s) and are not endorsed by BMJ. BMJ disclaims all liability and responsibility arising from any reliance placed on the content. Where the content includes any translated material, BMJ does not warrant the accuracy and reliability of the translations (including but not limited to local regulations, clinical guidelines, terminology, drug names and drug dosages), and is not responsible for any error and/or omissions arising from translation and adaptation or otherwise.

Open access This is an open access article distributed in accordance with the Creative Commons Attribution Non Commercial (CC BY-NC 4.0) license, which permits others to distribute, remix, adapt, build upon this work non-commercially, and license their derivative works on different terms, provided the original work is properly cited, appropriate credit is given, any changes made indicated, and the use is non-commercial. See: http://creativecommons.org/licenses/by-nc/4.0/.

\section{ORCID iD}

Julia V. Stingl http://orcid.org/0000-0002-9684-7753

\section{REFERENCES}

1 Flaxman SR, Bourne RRA, Resnikoff S, et al. Global causes of blindness and distance vision impairment 1990-2020: a systematic review and meta-analysis. Lancet Glob Health 2017;5:e1221-34

2 Naidoo KS, Leasher J, Bourne RR, et al. Global vision impairment and blindness due to uncorrected refractive error, 1990-2010. Optom Vis Sci 2016;93:227-34.

3 Czudowska MA, Ramdas WD, Wolfs RCW, et al. Incidence of glaucomatous visual field loss: a ten-year follow-up from the Rotterdam study. Ophthalmology 2010;117:1705-12.

4 Gerstenberger E, Stoffelns B, Nickels S, et al. Incidence of retinal detachment in Germany: results from the Gutenberg health study. Ophthalmologica 2021:244:133-40

5 Hopf S, Korb C, Nickels S, et al. Prevalence of myopic maculopathy in the German population: results from the Gutenberg health study. Br J Ophthalmol 2020;104:1254-9.

6 Hashemi H, Fotouhi A, Yekta A, et al. Global and regional estimates of prevalence of refractive errors: systematic review and meta-analysis. J Curr Ophthalmol 2018:30:3-22.

7 Wolfram C, Höhn R, Kottler U, et al. Prevalence of refractive errors in the European adult population: the Gutenberg health study (GHS). Br J Ophthalmol 2014;98:857-61.

8 Holden BA, Fricke TR, Wilson DA, et al. Global prevalence of myopia and high myopia and temporal trends from 2000 through 2050. Ophthalmology 2016;123:1036-42.

9 Morgan IG, Ohno-Matsui K, Saw S-M. Myopia. Lancet 2012;379:1739-48.

10 Cai X-B, Shen S-R, Chen D-F, et al. An overview of myopia genetics. Exp Eye Res 2019;188:107778.

11 Tedja MS, Haarman AEG, Meester-Smoor MA, et al. IMI - Myopia Genetics Report. Invest Ophthalmol Vis Sci 2019;60:M89-105.

12 Mirshahi A, Ponto KA, Hoehn R, et al. Myopia and level of education: results from the Gutenberg health study. Ophthalmology 2014;121:2047-52.

$13 \mathrm{Xu} \mathrm{L}$, Li J, Cui T, et al. Refractive error in urban and rural adult Chinese in Beijing. Ophthalmology 2005;112:1676-83.

14 Cooper J, Tkatchenko AV. A review of current concepts of the etiology and treatment of myopia. Eye Contact Lens 2018:44:231-47.

15 McCarthy CS, Megaw P, Devadas M, et al. Dopaminergic agents affect the ability of brief periods of normal vision to prevent form-deprivation myopia. Exp Eye Res 2007;84:100-7.

16 Wu P-C, Chen C-T, Lin K-K, et al. Myopia prevention and outdoor light intensity in a school-based cluster randomized trial. Ophthalmology 2018;125:1239-50.

17 Rose KA, Morgan IG, Ip J, et al. Outdoor activity reduces the prevalence of myopia in children. Ophthalmology 2008;115:1279-85.

18 Han X, Guo X, Lee PY, et al. Six-year changes in refraction and related ocular biometric factors in an adult Chinese population. PLoS One 2017:12:e0183364.

19 Guzowski M, Wang JJ, Rochtchina E, et al. Five-year refractive changes in an older population: the blue Mountains eye study. Ophthalmology 2003;110:1364-70.

20 Bomotti S, Lau B, Klein BEK, et al. Refraction and change in refraction over a 20-year period in the Beaver dam eye study. Invest Ophthalmol Vis Sci 2018;59:4518-24.

21 Li S-M, Lin C, Wan Y, et al. Five-year refractive changes in a rural Chinese adult population and its related factors: the Handan eye study. Clin Exp Ophthalmol 2018:46:873-81.

22 Lee KE, Klein BE, Klein R. Changes in refractive error over a 5-year interval in the Beaver dam eye study. Invest Ophthalmol Vis Sci 1999:40:1645-9.

23 Srinivasan S, Raman R, Swaminathan G, et al. Incidence, progression, and risk factors for cataract in type 2 diabetes. Invest Ophthalmol Vis Sci 2017:58:5921-9.

24 Saxena S, Mitchell P, Rochtchina E. Five-year incidence of cataract in older persons with diabetes and pre-diabetes. Ophthalmic Epidemiol 2004:11:271-7.

$25 \mathrm{Rim}$ THT, Kim M-H, Kim WC, et al. Cataract subtype risk factors identified from the Korea National health and nutrition examination survey 2008-2010. BMC Ophthalmol 2014; $14: 4$

26 Höhn R, Kottler U, Peto T, et al. The ophthalmic branch of the Gutenberg health study: study design, cohort profile and self-reported diseases. PLoS One 2015;10:e0120476.

27 Wendel-Vos GCW, Schuit AJ, Saris WHM, et al. Reproducibility and relative validity of the short questionnaire to assess health-enhancing physical activity. J Clin Epidemiol 2003:56:1163-9. 
28 Gudmundsdottir E, Arnarsson A, Jonasson F. Five-year refractive changes in an adult population: Reykjavik eye study. Ophthalmology 2005;112:672-7.

29 Wu S-Y, Yoo YJ, Nemesure B, et al. Nine-year refractive changes in the Barbados eye studies. Invest Ophthalmol Vis Sci 2005;46:4032-9.

30 Lee KE, Klein BEK, Klein R, et al. Changes in refraction over 10 years in an adult population: the Beaver dam eye study. Invest Ophthalmol Vis Sci 2002;43:2566-71.

31 Iribarren R. Crystalline lens and refractive development. Prog Retin Eye Res 2015:47:86-106.

32 Samarawickrama C, Wang JJ, Burlutsky G, et al. Nuclear cataract and myopic shift in refraction. Am J Ophthalmol 2007;144:457-9.

33 Brown NA, Hill AR. Cataract: the relation between myopia and cataract morphology. BrJ Ophthalmol 1987;71:405-14.
34 Hashemi H, Khabazkhoob M, Iribarren R, et al. Five-year change in refraction and its ocular components in the 40- to 64-year-old population of the Shahroud eye cohort study. Clin Exp Ophthalmol 2016;44:669-77.

35 Saw S-M, Chan Y-H, Wong W-L, et al. Prevalence and risk factors for refractive errors in the Singapore Malay eye survey. Ophthalmology 2008;115:1713-9.

36 Tomlinson A, Phillips Cl. Applanation tension and axial length of the eyeball. $\mathrm{Br}$ J Ophthalmol 1970;54:548-53.

$37 \mathrm{Lu}$ TL, Wu JF, Ye X, et al. Axial length and associated factors in children: the Shandong children eye study. Ophthalmologica 2016;235:78-86.

38 Storey P, Munoz B, Friedman D, et al. Racial differences in lens opacity incidence and progression: the Salisbury Eye Evaluation (SEE) study. Invest Ophthalmol Vis Sci 2013:54:3010-8. 